\title{
ENSAIO E INTERPRETAÇÃO DO BRASIL NO MODERNISMO VERDE-AMARELO (1926-1929)
}

Essay and Brazil's interpretation by verde-amarelo modernism (1926-1929)

Ensayo e interpretación de Brasil en el modernismo verde-amarelo (1926-1929)

LORENNA RIBEIRO ZEM EL-DINE ${ }^{*}$

DOl: http://dx.doi.org/10.1590/\$2178-14942019000200007

'Fundação Oswaldo Cruz, Rio de Janeiro - RJ, Brasil.

*Doutora em História das Ciências e da Saúde pela Casa de Oswaldo Cruz, Fundação Oswaldo Cruz, Rio de Janeiro, Brasil. (Irzedine@gmail.com). ORCID iD: https://orcid.org/0000-0002-4055-8733.

Artigo recebido em 10 de março de 2019 e aceito para publicação em 5 de julho de 2019. 
ENSAIO E INTERPRETAÇ̃̃O DO BRASIL NO MODERNISMO VERDE-AMARELO (1926-1929)

\title{
RESUMO
}

Este artigo analisa publicações da vertente Verde-amarela/Anta do modernismo paulista, entre os anos de $1926 \mathrm{e}$ 1929, no jornal diário Correio Paulistano. Discute a hipótese de que as proposições de Cassiano Ricardo, Menotti Del Picchia, Plínio Salgado e demais participantes do grupo, para o estudo do Brasil e dos brasileiros, devem ser analisadas tendo em conta, além do discurso de valorização da intuição estética, seus diálogos com os ensaios de interpretação nacional na tradição brasileira e latino-americana, os quais os verde-amarelos teriam considerado como forma adequada de aproximação com o discurso científico sobre a realidade brasileira.

PALAVRAS-CHAVE: Modernismo; Interpretação do Brasil; Ensaio; Movimento Verde-amarelo/Anta; Relações raciais; José Vasconcelos.

\begin{abstract}
The article analyzes authors of the group Verde-amarelo/Anta, a trend of paulista modernism. Cassiano Ricardo, Menotti Del Picchia, Plínio Salgado published articles on the newspaper Correio Paulistano between 1926 and 1929. I argue they understood Brazil and Brazilian people through the Brazilian and Latin American tradition of nation essays, as Alberto Torres and José Vasconcelos. Those essays were a part of the historical and sociological culture of the early twenty century. Then I conclude that the authors had a more complex relationship with scientific discourse than the historiography of the modernism admit, beyond the aesthetic intuition and an anti-scientific discourse.
\end{abstract}

KEYwORDS: Modernism; Interpretations of Brazil; Essay; Verde-amarelo/Anta movement; Races relations; José Vasconcelos.

\section{RESUMEN}

Este artículo analiza publicaciones de la vertiente Verde-amarela/Anta del modernismo paulista, entre los años 1926 y 1929, en el diario Correio Paulistano. Sostengo la hipótesis de que para analizar las proposiciones de Cassiano Ricardo, Menotti Del Picchia, Plínio Salgado y demás participantes del grupo, para el estudio de Brasil y de los brasileños, se debe tener en cuenta, además del discurso de valorización de la intuición estética, sus diálogos con los ensayos de interpretación nacional en la tradición brasileña y latinoamericana, que los verde-amarelos habrían considerado como forma adecuada de acercamiento con el discurso científico sobre la realidad brasileña.

PALABRAS CLAVE: Modernismo, Interpretación de Brasil; Ensayo; Movimiento verde-amarelo/anta; Relaciones raciales; José Vasconcelos. 


\section{INTRODUÇÃO}

naliso neste artigo a apologia dos ensaios de interpretação nacional por parte da ver-
tente verde-amarela/anta do modernismo paulista, manifestada em artigos publicados no Correio Paulistano, entre 1926 a 1929. Argumento que a valorização da intuição, em detrimento dos processos analíticos do conhecimento, embora uma marca reconhecida do grupo de Plínio Salgado, Menotti Del Picchia e Cassiano Ricardo (Jardim, 2016), ${ }^{1}$ não significou um contraponto irremediável a formas reflexivas de apreensão da realidade. A meu ver, a tensa relação dos verde-amarelos com o discurso científico terminaria por respaldar a tradição ensaística nacional e latino-americana, aqui compreendida como parte da cultura historiografia e sociológica brasileira das primeiras décadas do século XX.

Considero nesta análise a importância de situarmos o modernismo de São Paulo no panorama das mudanças ocorridas no cenário intelectual brasileiro do início do século XX e de nos lembrarmos dos caminhos pelos quais se deu a institucionalização das ciências sociais em distintos contextos nacionais (Lepenies, 1996; Martins, 2003), considerando as tensões entre os literatos e os cientistas, que permearam o processo de especialização dos saberes no Brasil (Sá, 2006). Com base nesse enfoque, apesar da marca anti-intelectualista verde-amarela, a participação desse grupo na interpretação do país, tarefa que os intelectuais dos anos 1920 estabeleceram como fundamental, pode, enfim, ser examinada.

Investigo as publicações verde-amarelas como discursos que não só defenderam a prerrogativa do artista como intérprete da brasilidade, mas também tencionaram outras perspectivas a partir das quais se produzia conhecimento sobre o Brasil e os brasileiros. Ao chamar a atenção para polêmicas e reflexões que reverberarão nos desdobramentos do modernismo em ensaios de caráter sócio-histórico de maior fôlego, publicados na década seguinte, ${ }^{2}$ cogito a inclusão da reflexão dos verde-amarelos sobre o ensaísmo no escopo de uma "sociologia modernista" ou como parte da "floração" que antecede o "canteiro sociológico" mais abundante dos anos 1930 (Martins, 2013: 61) e, consequentemente, também a inclusão do grupo no rol dos chamados intérpretes do Brasil.

A eleição dessa perspectiva tem em vista que, nos últimos anos, a pesquisa em hemerotecas digitais brasileiras como a da Biblioteca Nacional, a abordagem transnacional e o interesse da historiografia sobre a formação de redes intelectuais implicam novos vieses para uma história intelectual do modernismo. Acerca dos verde-amarelos, em periódicos dos anos 1920, vem sendo possível mapear desde referências conhecidas a obras de brasileiros como Euclides da Cunha, Alberto Torres, Oliveira Vianna e Roquette-Pinto até citações mais dispersas a autores latino-americanos, como o uruguaio José Enrique Rodó e os peruanos 
Francisco Garcia Calderón e José Carlos Mariátegui, ou ainda mais sistemáticas, como no caso de José Vasconcelos (El-Dine, 2017; Coelho, 2018). Além disso, é possível notar o contato que tiveram com obras como as do alemão Hermann Keyserling e as do norte-americano Waldo Frank, que nos anos 1920 e 1930 elegeram a América Latina como objeto de suas reflexões e construíram sólidas redes intelectuais no continente ( Berriel, 1987; Lino, 2009; Faria, 2013).

Como escritores contumazes em periódicos e revistas, os verde-amarelos se inseriram cada qual de um modo particular nos debates internos ao modernismo, bem como repisaram a forma periodística do ensaísmo hispano-americano (Skirius, 2006: 12). Suas publicações reagiram aos debates intelectuais e aos acontecimentos da época, transitando sobre o terreno comum da percepção da decadência do legado cultural europeu e da crise da ordem liberal no período no entreguerras. De fato, foi também interpelando esse contexto intelectual e a própria crise do regime republicano brasileiro que os verde-amarelos e seus pares se voltaram para o estudo do passado nacional e do brasileiro, produzindo intepretações do país que tanto se acercaram quanto deslocaram os padrões científicos estrangeiros .

Ao mesmo tempo, não se pode esquecer que, como editores da revista literária Novíssima (1923-1926), Cassiano Ricardo e Menotti Del Picchia ensaiaram uma aproximação com escritores latino-americanos, chegando a reunir um grupo eclético de colaboradores, do qual participaram o mexicano Federico Gamboa, os uruguaios Juana de Ibarbourou e Vítor Perez Petit, e os argentinos Alfonsina Storni, Lorenzo Stanchina, Manuel Galvéz, Nicolás Olivari e Benjamín de Garay (Guelfi, 1989: 43). ${ }^{3}$

Inicialmente, analiso o lugar da crítica aos cientistas e aos procedimentos da ciência na conformação do verde-amarelismo e de seus contrapontos aos pares modernistas. Em seguida, argumento queos verde-amarelos elegeram a tradição ensaística brasileira e latino-americana como base teórica de seu movimento, numa tentativa de se diferenciarem de outras correntes do modernismo, e chamo a atenção para suas leituras de Alberto Torres. Por fim, sugiro uma relação entre ensaio e a interpretação do Brasil e dos brasileiros proposta pelos verde-amarelos, tendo em vista seus diálogos com a obra de José Vasconcelos.

Ao longo do artigo, procuro observar a interlocução dos verde-amarelos com outros modernistas e intelectuais da época, especialmente com Graça Aranha, Oswald de Andrade e Mário de Andrade, a fim de estabelecer o contexto de suas reflexões. 


\section{A CIÊNCIA E O PROJETO VERDE-AMARELO NO INTERIOR DO MODERNISMO PAULISTA}

E ntre fins do século XIX e começos do XX, em meio ao processo de especialização do conhecimento no Brasil, a prerrogativa da interpretação nacional foi disputada por literatos e cientistas. As transformações resultantes da crise da cultura bacharelesca e do modelo intelectual "polivalente", figura que transitava pelos diversos saberes, foi, muitas vezes, representada nos discursos dos cientistas e de outros atores intelectuais da época pela oposição entre diletantismo e saber prático (Sá, 2006). Além disso, um pouco mais tarde, a mesma oposição serviu aos verde-amarelos para assinalarem o contraponto entre os velhos e os novos atores do cenário intelectual brasileiro, num contexto em que os modernistas de São Paulo, já distribuídos em diferentes correntes, tencionavam cada vez mais os limites entre arte e política.

Nos anos finais da década de 1920, os verde-amarelos se referiram com frequência ao que havia de mais concreto na discussão sobre as fronteiras entre literatura e ciência, isto é, a separação dos espaços de reconhecimento e sociabilidade intelectual. Cassiano Ricardo criticou a recorrência com que a Academia Brasileira de Letras ( $A B L$ ) vinha substituindo os "homens de letras" pelos "homens de ciência" ou "de poucas letras" ( 25 out. 1926). No ano seguinte, Menotti Del Picchia, que foi um participante ainda mais contumaz desse debate, criticou a frequência com que os médicos vinham se metendo em departamentos alheios aos de suas especialidades. Na sua visão, era uma afronta que os médicos, após conseguirem êxito em sua profissão, se entregassem nas horas vagas a uma "artificiosa manufatura de sonetos", com os quais se ofereciam ao recebimento das "glórias acadêmicas", rebaixando o "valor superior da arte" (7 abr. 1927).

Além de um sintoma das transformações pelas quais passava o campo intelectual brasileiro, há nessa crítica de Menotti Del Picchia um argumento que se desdobra na rejeição à arte como passatempo e ao artista enclausurado em sua torre de marfim. Nesse sentido, boa parte da retórica do grupo será empreendida na convocação dos intelectuais da época ao conhecimento da realidade nacional. Tal como outros intelectuais de seu tempo, que escreveram sob o impacto da Primeira Guerra Mundial, da crise do modelo civilizacional europeu e do ideário liberal, bem como do agravamento da crise política brasileira, que foi interpretado como a falência do regime republicano nos moldes em que foi instituído na virada para o século XX, os verde-amarelos consideraram diagnosticar e solucionar os problemas nacionais como uma missão geracional. ${ }^{4}$ Paradoxalmente, foi esse mesmo tema que pavimentou o caminho para a adesão dos verde-amarelos ao discurso científico. 
No verso disso, entretanto, o contraponto ao modo de conhecer da ciência foi uma moeda corrente, seja nas críticas dos verde-amarelos ao passadismo literário, seja nos seus embates com outros modernistas. Nesses casos, o argumento divergente seria construído sobre a negativa aos modelos europeus e à replicação de fórmulas artísticas que consideraram equivalentes aos procedimentos sistemáticos da ciência. Para os verde-amarelos, possivelmente imbuídos de ecos da crítica romântica à invasão da ciência a territórios alheios aos seus, havia certo parentesco nos processos que tornavam os parnasianismos, mas também modernistas como Oswald de Andrade e Mário de Andrade, muito teóricos, ao passo que a poesia nacional deveria ser espontânea e traduzir sinceramente a realidade brasileira. ${ }^{5}$ Por essa razão, segundo Cassiano Ricardo, a "revelação do Brasil" era prerrogativa da poesia e da sua expressão sentimental "mais concreta e mais pura" que a linguagem dos cientistas (11 jan. 1927).

Nessa interpretação, aliás, os verde-amarelos coincidiriam com o ponto de vista de Graça Aranha, para quem os processos analíticos da ciência produziam um entendimento fragmentário da realidade nacional (Jardim, 2016: 25). Para Cassiano Ricardo, por exemplo, o artista se distanciava da pátria se a tomasse por seu objeto de estudos, ao passo que sua subjetividade projetada sobre o mundo exterior seria um reflexo da realidade nacional. A seu ver, a arte era capaz de captar por si só a essência nacional, e o processo de criação realizava uma fusão harmoniosa entre o artista e a pátria, dispensando a mediação dos processos científicos (Velloso, 1983: 48).

Em meados de 1925, os verde-amarelos se referiram à poesia Pau Brasil como um "doloroso experimentalismo científico". Nas palavras de Cassiano Ricardo e Plínio Salgado, Oswald de Andrade se inspirara no trabalho dos "fisiologistas", que "costumam tirar certas partes do cérebro dos animais, para ver se eles andam, sentem, gritam", e estaria fazendo o mesmo com o estilo brasileiro "ainda em ensaio, a ver se ele exprime alguma coisa" (Hélios, 28 set. 1925).

Apesar da convergência dos modernistas em torno do tema da brasilidade, ocorrida especialmente a partir de 1924 (Jardim, 2016), cada vez mais as diferenças entre os verde-amarelos, Oswald de Andrade e Mário de Andrade se aprofundaram. Graça Aranha foi isolado por parte do grupo paulista, e Sergio Buarque de Holanda escancarou as divergências entre os diversos grupos do movimento com a publicação de 0 lado oposto e outros lados, em 1926. De todo modo, Oswald de Andrade e os verde-amarelos se mantiveram afinados no entendimento de que a intuição seria o caminho mais adequado à apreensão da brasilidade, ao passo que Mário de Andrade privilegiaria a pesquisa sistemática da cultura nacional (Ibidem: 73; 81; 95).

Por outro lado, considerando que os discursos desses escritores foram se constituindo uns contra os outros (Ricupero, 2018: 896), muitas vezes parecem ser tênues os limites no tra- 
tamento de questões como a crítica aos estrangeirismos e à erudição, comumente desdobrada numa apreciação ambivalente do legado europeu, e a valorização do índio na construção do discurso nacional, para ficarmos apenas na apreciação dos debates entre Oswald de Andrade e os verde-amarelos.

Em relação ao mal-estar brasileiro com a influência estrangeira, Oswald de Andrade, na fórmula antropofágica, ao tomar o ato de devorar o que vinha de fora como definidor do Brasil, teria apresentado uma "solução diferente" da "denúncia da importação de ideias e instituições produzidas na Europa" (Ricupero, 2018: 875), que esteve tão a gosto dos verde-amarelos. Além disso, embora a metáfora da alimentação também tenha sido empregada também por esses escritores, seu uso serviu para denunciar o excesso de erudição e de estrangeirismos entre os brasileiros que, na expressão de Cassiano Ricardo, seriam mais "ruminantes de cultura" do que homens de ação (Ricardo, 07 set. 1926).

A metáfora descreveria, portanto, uma suposta doença do brasileiro, e não a terapêutica da "absorção dos ingredientes desejáveis de um corpo estrangeiro para o enriquecimento do organismo devorador", como no sentido pretendido por Oswald de Andrade, segundo Netto (2004: 98). De qualquer maneira, é curioso encontrar o tema do canibalismo num texto de Plínio Salgado, Carta antropófaga, de 1927, um pouco antes do aparecimento da Revista de Antropofagia, em 1928, e cogitar que Oswald de Andrade tenha encontrado ali uma inspiração para seu manifesto (Johnson, 1988; Cuccagna, 2004; Ricupero, 2018).

Sobre a importância que esses escritores deram à herança indígena como definidora da brasilidade, a Antropofagia destacou a violência do índio como caminho de integração à cultura nacional. 0 índio foi representado como o antropófago que devora a cultura do colonizador, seleciona para si alguns elementos e lhes dá um novo sentido, brasileiro, enquanto os verde-amarelos valorizaram a passividade do índio, que se teria deixado absorver pelo colonizador, para viver subjetivamente na alma nacional (Jardim, 2016: 99, 103 e 121). Conforme o Manifesto Nhengaçu, de 1929, o nacionalismo brasileiro era sem preconceitos porque o índio atuava como o mediador dos conflitos, aplainando as arestas de um povo formado pela intensa imigração e reunião de indivíduos procedentes de diversas nacionalidades (Picchia et. al. 1929).

Já nessa época e depois, na década de 1940, quando Cassiano Ricardo releu esse tema, durante a polêmica com Sérgio Buarque de Holanda sobre o sentido da cordialidade brasileira, o índio verde-amarelo evoca o "bom selvagem" e descreve o brasileiro como "homem bom" e cordial, "no sentido de 'homem síntese'", que teria sido cunhado por José Vasconcelos, em La raza cósmica, em 1925 (Ricardo, 1959: 34). 


\section{IMAGINAÇÃO E REALIDADE NO PENSAMENTO BRASILEIRO}

pesar de a intuição ter sido apontada pelos verde-amarelos como o caminho mais
adequado para a interpretação do Brasil, a partir de 1926, o ensaio se firmaria cada vez mais como um caminho interpretativo que dava conta desse aspecto. Foi esse o rumo indicado em Literatura e política, quando Plínio Salgado sugeriu um descolamento com relação ao modernismo literário e a reconfiguração das bases intelectuais do verde-amarelismo, fazendo alusão à tradição ensaística brasileira:

Sentir-se-á nestas páginas a impressão que me tem ficado da obra de Alberto Torres, das ponderações de Tavares Bastos, do nosso pensamento nacional que, com feições contrastantes, espelha-se na literatura social e política de Oliveira Vianna, Pontes de Miranda, Licínio Cardoso, Roquette-Pinto, Tristão de Athayde, Jackson de Figueiredo [...]. Também será observada a influência dos depoimentos e comentários de Euclides da Cunha (1927: XI-XII).

Nesse livro, Plínio Salgado convoca os intelectuais a estabelecerem as bases da nacionalidade e não deixa de fora os homens de ciência, aos quais estenderia a obrigação de olhar para a realidade nacional com olhos brasileiros. As referências à tradição ensaísta brasileira e latino-americana se tornaram mais frequentes a partir desse contexto. Menotti Del Picchia, em 1959, se lembrou da parceria com o historiador Alfredo Ellis Junior, que, como "erudito do grupo revolucionário", contribuiu para equacionar "problemas políticos, históricos, sociais e filosóficos sugeridos pelo movimento", assumindo o "trabalho de disciplinar, através de ensaios expositivos, os intuitos da cruzada renovadora do pensamento nacional". Em resumo, segundo Picchia, as suas "investigações de caráter histórico" teriam oferecido material "para os estudos do grupo combativo" (apud Ellis, 1997: 24).

A primeira edição de Raça de gigantes (1926) integrou a coleção lançada pela editorial Hélios, de Cassiano Ricardo e Menotti Del Picchia. ${ }^{6}$ Segundo a propaganda que foi veiculada por essa editora, o livro de Alfredo Ellis Junior apresentava "uma reconstituição antropo-social do paulista, desde os primeiros séculos do povoamento, com focalizações sintéticas e analíticas dos fenômenos psicológicos e sociais do planalto paulista, desde o bandeirismo até a implantação das lavouras de café". ${ }^{7}$ A relação destacada do texto da editora previa a colaboração entre os processos de conhecimento da arte ("focalizações sintéticas") e da ciência ("analíticas"), sinalizando, nesse caso, que os saberes das ciências humanas e sociais são aliados da construção de conhecimento sobre a realidade brasileira.

Dando conta dessa articulação entre modernismo e ensaísmo, Candido Motta Filho escreveu que Graça Aranha sintetizara o pensamento de Alberto Torres, quando "disse que a história do Brasil era a história da nossa imaginação" (1927: 27). Motta Filho escreveu um 
ensaio sobre Alberto Torres, Alberto Torres e o tema da nossa geração (1931), que foi publicado primeiro nos rodapés do Correio Paulistano, entre 1927 e 1928, e, mais tarde, impresso pela Schmidt Editor-Rio, com prefácio escrito por Plínio Salgado. Nesse texto, Plínio Salgado apresentou a si e a Motta Filho como porta-vozes de "uma geração sacrificada", que começou a exercer sua crítica sobre a República, notando "o contraste entre as realidades da Nação e o espírito que animava a sua Constituição e as suas leis" (Salgado, 1931: II), ao mesmo tempo que se familiarizavam com as realidades brasileiras estudadas pelas obras de Oliveira Vianna e Alberto Torres.

Alberto Torres, na visão de Motta Filho, havia sido um político discreto, mas profundo, além de um sociólogo com "visão pragmática das coisas brasileiras" (1931: 17-20). Suas ideias coincidiam com as de pensadores como Tavares Bastos, Joaquim Nabuco e Euclides da Cunha e estariam em contraponto ao alheamento de intelectuais como Rui Barbosa. Segundo Motta Filho, para Alberto Torres, o brasileiro estava acostumado à "força apaziguadora" da imaginação, costumava adiar a verdade e não conseguia impor sua personalidade nacional, por isso precisava urgentemente substituir a imaginação por uma visão da realidade brasileira (Ibidem: 28-29). Alberto Torres não aceitava o espírito catedrático europeu, observava e falava com consciência americana e brasileira, e "o que ele diz, na observação local dos problemas nacionais, está hoje generalizado e aceito pelas mais potentes autoridades sociológicas do mundo" (Ibidem: 48).

Essa leitura de Candido Motta Filho evoca sentidos paradoxais dessa época, que conciliava a afirmação da cultura local, o questionamento do legado europeu, mas também a familiaridade com autores que produziram da Europa críticas à cultura ocidental e que, buscando referenciais culturais externos ao velho continente, voltavam as atenções para outros cenários no mundo, como Ásia, África e América Latina. Considerando-se o contexto modernista, cabe lembrar que a crítica à cultura ocidental também foi uma questão central para a Antropofagia e que, desde o lançamento da poesia Pau Brasil, em 1924, Oswald de Andrade negou várias vezes a identificação com o primitivismo europeu (Ricupero, 2018: 882 e 891). ${ }^{8}$

No capítulo "A terra e sua gente", Motta Filho cita o A decadência do Ocidente, de Oswald Spengler, e ressalta uma de suas premissas: a de que a vitalidade de um povo dependia de sua convivência harmônica com a terra e de sua compreensão sobre os caracteres geopolíticos de sua conduta (1931: 47). Além disso, afirma ter se convencido da semelhança "entre o modernismo da civilização da América e o processo da civilização" no Egito antigo (Ibidem: 67), depois de ler um artigo do crítico de arte alemão Wilhelm Worringer, 0 americanismo da civilização egípcia, que teria sido publicado na Revista do Ocidente, em 1926. 
Motta Filho argumenta que o Egito, antes da civilização americana, por conta de suas características geográficas, teria deparado com a necessidade de "criar uma personalidade inédita com a absorção de raças e gênios contrastantes" (Ibidem). Também na América, diante da mesma urgência, existiria "uma força oculta que faz esquecer ao estrangeiro seu país de origem", conforme o adágio egípcio: "o estrangeiro que bebe a água do Nilo esquece o seu país Natal" (Ibidem: 67-68). ${ }^{9}$

Diante disso, para Motta Filho, a solução para o problema racial no Brasil não passava pela discussão sobre "raças puras e outros bizantinismos de civilizações extenuadas" (Ibidem: 68). Alberto Torres, segundo Motta Filho, "não se impressionava por ver algumas populações interiores atacadas de moléstias tropicais"; ele as compreendia como "feridos de uma refrega e também como atestado de que havia uma luta séria e dramática. Mas nunca degeneração" (Ibidem: 69). Há aqui uma coincidência com os discursos médico-sanitaristas da época, para os quais o brasileiro do interior não sofria de mácula racial, mas estaria abandonado pelas elites políticas republicanas (Lima e Hochman, 1996).

Em todo caso, Motta Filho diria que o pessimismo em relação ao brasileiro que era disseminado por ensaios como o Retrato do Brasil (1928), de Paulo Prado, que retratava o Brasil e os brasileiros "em 'pose' de tristeza e de desânimo", reproduzia, na realidade, um "ponto de vista ocidental". Conforme afirmava, Graça Aranha era "menos civilizado que o Sr. Paulo Prado", pois considerava o trabalho e a alegria do brasileiro (30 nov. 1928).

\section{UM PROGRAMA DE ESTUDOS PARA A INTERPRETAÇÃO DO BRASIL}

ssim, o debate que ficara restrito ao campo das artes e à aquisição de um estilo nacio-
nal se voltava para a elaboração de um programa, baseado na obra de Alberto Torres e de outros ensaístas, para a "observação local dos problemas nacionais". A primeira coisa a ver era o profundo abismo existente entre os chamados dois brasis. A relação entre o litoral e o interior do país, constantemente retomada pelos ensaios históricos e sociais do Brasil, nas primeiras décadas do século XX (Lima, 1999), foi também destacada por Plínio Salgado, em Literatura e política.

O escritor idealizou o interior como um lugar onde os traços autênticos da cultura brasileira estariam resguardados da ameaça dissolvente do cosmopolitismo do litoral. Entretanto, apesar da ênfase sobre um suposto "mal urbano", Salgado sugeriu uma aliança entre aquelas duas tendências: "o Sertão deve dar à Cidade a sua alma e receber desta os benefícios da civilização. Uma e outro devem respirar [...] numa atmosfera de tradições históricas e aspirações comuns" (1927: 83). 
Em 1927, Plínio Salgado escreveu que, a seu ver, o Facundo (1845) do argentino Domingo F. Sarmiento tomava outro sentido: "Eu via o homem brotar da Terra e avançar para a cidade. Eu via a grande cortesã [...] invadida, por uma manada de antas arrasadoras do cosmopolitismo" (19 mai. 1927). Alguns meses antes, ele publicou que Sarmiento, ao visitar o túmulo de Facundo Quiroga, teria afirmado que o "sangue bárbaro" deste pulsaria sempre em sua pátria, "atenuado pela civilização", porém com "toda a sua força nativa" (23 jan. 1927), o que, na sua visão, era um dado mais importante que o próprio livro escrito por Sarmiento.

Além disso, alertou que o Brasil não deveria repetir o erro do país vizinho, que teria se tornado "uma nação rica, mas sem traços expressivos de originalidade" (8 fev. 1927). Ao contrário da Argentina, o Paraguai seria um exemplo mais edificante, porque "soube conservar a sua feição, mais fiel a terra e à raça" (Ibidem). Era necessário ouvir "o aviso formidável de Euclides da Cunha e o exemplo argentino, que Sarmiento estampou no seu Facundo", a fim de "preparar uma grande nacionalidade americana" (21 jul. 1927).

A relação ambígua entre a atração pela cultura europeia e a tentativa de deslocamento dos padrões culturais eurocêntricos seria retomada nos anos seguintes. Em 1928, Menotti Del Picchia comemorou a prosperidade econômica das pequenas cidades do oeste paulista e seus desdobramentos, que permitiam neutralizar o exílio interno do brasileiro (21 abr. 1928). Cassiano Ricardo celebrou, no ano seguinte, a ampliação das estradas de ferro e de rodagem, das "estações radiotelegráficas e da telefonia automática", chamando a atenção para a possibilidade de o país, por meio do incremento das comunicações, conhecer e tomar posse da própria cultura, bem como, pelos mesmos instrumentos, se abrir ao influxo externo e se tornar menos exilado do mundo (27 mai. 1928). Em ambos os casos, embora a modernização tenha sido vista como uma oportunidade para projetar valores "autênticos" da cultura brasileira, sua celebração suaviza a ideia de uma oposição irremediável ao cosmopolitismo.

As referências continentais ganharam maior projeção nessa época. Menotti Del Picchia, lembrando novamente Facundo, interpretou as sucessivas revoltas militares que tencionavam o regime republicano brasileiro desde sua implementação e as interpretou como repetições de um "fenômeno americano", o caudilhismo (6 jul. 1927). A apreensão do Brasil sob um parâmetro continental foi reforçada, na mesma época, pela releitura de 0 sonho da raça (1924), de Alarico Silveira. 0 texto se referia à mítica descida dos tupis do interior do continente, dos territórios da Bolívia e do Peru, até o litoral brasileiro, uma migração que explicaria a nostalgia do bandeirantismo histórico pelo Oeste, e que teria sido reeditada no anseio da época pela interiorização. Tal narrativa, pela óptica de Alarico Silveira, acenava para os laços culturais, autóctones, mais fortes que as artificiais divisões territoriais entre os países sul-americanos (nov.-dez. 1924). 
Num sentido próprio e conectado com o tema racial, 0 sonho da raça reiterava a importância do espaço e do território para o encontro com um sentido brasileiro e americano. A interiorização e o urgente encontro com a "terra" foram temas recorrentes de Cassiano Ricardo, em 1926 e 1927, incluindo suas notas "impressionistas" sobre a obra de Edgard Roquette-Pinto, que lembram a leitura de Candido Motta Filho da obra de Alberto Torres. Nelas, Cassiano Ricardo destacaria: "O que nos falta, disse Roquette Pinto, é conhecer o que se tem descoberto e conquistado. 0 que nos falta, direi eu, é compreendê-lo na sua imensa significação. É penetrá-lo nas suas fontes de riqueza. É investigá-lo nas suas condições de vida" (14 set. 1927).

A obsessão de Cassiano Ricardo pelo "sertão" dividiu espaço com a idealização da população mestiça do interior. Ele ressaltou, em publicações no Correio Paulistano e em Martim Cererê (1928), a importância das três raças na história paulista e brasileira, mas sob o ponto de vista de uma hierarquia de funções (Moreira, 2001). No que diz respeito ao negro, Ricardo se distanciou tanto da negativa de Alfredo Ellis Junior, em Raça de gigantes (1926), a respeito da pouca participação do negro na sociedade bandeirante, quanto da opinião de Ellis Junior, de que teria sido precária a adaptação fisiológica do negro às condições ambientais de São Paulo (1928: 44). Assim, o ponto de vista de Cassiano Ricardo terminaria ficando mais próximo do de Alberto Torres, que, conforme Candido Motta Filho destacava à época, considerava ser "uma superstição essa a de afirmar a degeneração do negro entre nós" (1931: 69).

Já Menotti Del Picchia afirmou que a solução do problema racial brasileiro dependia exclusivamente da "plasmação étnica", nas condições especificas do clima e do ambiente brasileiro. Acerca disso, atestava que a "mistura bizarra" entre "o luso, o preto e o índio", "sob o nosso sol", havia formado "um tipo tão prodigioso de energia física e de iniciativas, que conseguiu desbravar, fixar-lhe as fronteiras, possuir e defender uma das pátrias geograficamente maiores do mundo" (26 ago. 1926). Com esses argumentos, rechaçava a adoção de políticas imigratórias pelo estado de São Paulo, contrapondo-se às que haviam sido propostas por Alfredo Ellis Junior, na condição de deputado estadual, e pelo sociólogo Oliveira Vianna, em 1926, as quais propunham a adoção de critérios raciais para a seleção dos imigrantes (El-Dine, 2016). Conforme Menotti Del Picchia se justificava: "Precisamos de braços e todos os braços são bons, quando são sadios moral e fisicamente, e estão habituados ao trato da terra" [...], "o que se deverá evitar [...] será [a] entrada de elementos defeituosos ou pouco sadios, rebeldes à disciplina social, perigosos, portanto, à ordem do agregado" (26 ago. 1926). ${ }^{10}$

Os pontos de vista de Alfredo Ellis Junior e Oliveira Vianna, por ultrapassarem esses cuidados, ao ver de Menotti Del Picchia, ilustravam uma "forma puramente lírica" de tratar 
o tema da imigração no Brasil (Ibidem). Ao reprovar determinadas linhas de interpretação da questão racial pelo ensaísmo da época, Picchia demonstrava conhecer o debate racial e eugenista na época, porém fazia um aceno aos intelectuais mais afinados com o discurso científico, endossando outro tipo de interpretação histórica, a qual enalteceria as três raças formadoras da população brasileira (El-Dine, 2017: 250).

\section{A MISCIGENAÇÃO E O ENSAíSMO LATINO-AMERICANO}

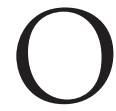

intelectual e ensaísta mexicano José Vasconcelos foi referência recorrente nas publicações de Cassiano Ricardo, Menotti Del Picchia e Plínio Salgado. As primeiras menções à sua obra mais famosa, La raza cósmica (1925), foram contemporâneas da discussão acerca da proposta de Plínio Salgado de elegerem um totem nacional quando, em 1927, os verde-amarelos assumiram o nome de Movimento da Anta, coroando a preferência de Plínio Salgado por símbolo indígena (El-Dine, 2017).

Além do discurso otimista acerca da miscigenação no continente americano, que, segundo José Vasconcelos, formaria um mestiço cósmico e seria a síntese de todas as raças anteriormente existentes (Ascenso, 2013), é provável que suas posições ambivalentes em relação à ciência tenham chamado a atenção do grupo paulista. Segundo José Vasconcelos, "la historia empírica, enferma de miopía, se pierde en el detalle" e "cae en la puerilidad de la descripción de los utensilios y de los índices cefálicos y tantos otros pormenores, meramente externos que carecen de importancia si se les desliga de una teoría vasta y comprensiva" (1948: 15). Diante disso, propunha uma fórmula que faria sentido aos verde-amarelos: "Ensayemos, pues, explicaciones, no con fantasía de novelista, pero sí con una intuición que se apoya en los datos de la historia y de la ciencia" (Ibidem: 15-16).

Tal como a obra de José Vasconcelos, a simbologia da Anta representou a evocação de passado mítico e um aceno na direção do futuro. Mais do que se ater à realidade antropológica do brasileiro, Plínio Salgado pretendeu elaborar um discurso nacional condizente com um país que seria o berço do "homem síntese" idealizado por José Vasconcelos. A escolha da Anta se justificava por sua referência à raça, que, na visão de Plínio Salgado, soube deixar-se assimilar pela mestiçagem e desaparecer, abrindo o caminho para o futuro sugerido pelo intelectual mexicano.

A partir de 1926, os verde-amarelos viram São Paulo como o cenário ideal para a realização daquela tese, considerando o grande afluxo de imigrantes que a cidade recebia e sua exposição à influência subjetiva do tupi (Picchia et. al. 1929). 0 papel visionário do indígena, 
segundo os verde-amarelos, que soube desaparecer no contato com o colonizador mas se manter vivo na alma do brasileiro, a fim de realizar o destino nacional (Ibidem), lembra a filosofia da história de José Vasconcelos, embora o indígena nas publicações do grupo paulista pareça ocupar o lugar da raça ibérica em La raza cósmica.

Para José Vasconcelos, a história da humanidade era a sucessão de distintas civilizações que florescem e decaem até o aparecimento de uma civilização definitiva. Em cada uma das civilizações anteriores, houve a predominância de um tipo racial, respectivamente, o índio, o negro, o mongol e, finalmente, o branco, cujo predomínio se estendia desde a civilização grega até a contemporânea, havendo passado pelos impérios formados pela estirpe ibérica e anglo-saxã no continente americano. ${ }^{11}$ Cada um daqueles quatro tipos raciais, depois de cumprirem a missão a que estavam predestinadas, tendiam ao desaparecimento. No entanto, a missão reservada ao branco era criar condições técnicas para a reunião de todas aquelas raças existentes, que então se mesclariam até formar uma raça mestiça no continente americano. Com isso, uma nova civilização povoaria os trópicos, alcançando o último estágio de desenvolvimento da humanidade, que José Vasconcelos chamou de estágio estético (1948: 33).

Com base nesse quadro, José Vasconcelos afirmava que, embora os anglo-saxões houvessem contribuído para o desenvolvimento científico com potencial para unir reunir diferentes raças e povoar todos os continentes, os povos de origem ibérica teriam a vantagem da maior propensão à mescla inter-racial e não desenvolveram, como os Estados Unidos, um ideal de pureza racial que resultou na eliminação do índio e na separação do negro (Ibidem: 26-27; 29). 0 preconceito desses povos com relação à mestiçagem teria sido traduzido em falsas premissas científicas, com as quais justificavam sua ascendência sobre os países americanos de origem ibérica.

A preocupação de José Vasconcelos com a afirmação da parte ibérica do continente frente aos Estados Unidos, contudo, não encontrou paralelo entre os verde-amarelos - mesmo entre Menotti Del Picchia e Candido Motta Filho, que, diante da sugestão de Plínio Salgado sobre a Anta, propuseram que a herança europeia fosse homenageada pelo símbolo da Loba (Picchia, 12 jan. 1927; Motta Filho, 20 jan. 1927). Além disso, embora Plínio Salgado tenha assinalado a incapacidade europeia de sondar os "desígnios da Espécie", chegando com isso a uma formulação muito próxima à de José Vasconcelos, nas suas correções à perspectiva científica, o ibérico foi incluído nesse diagnóstico. Na sua interpretação, ao contrário dos portugueses, que teriam descoberto o Brasil por acaso, os tupis migraram para o litoral porque tiveram a "profunda intuição" do "segredo político do futuro e do destino do continente sul-americano" (Salgado, 1926: 42). 


\section{CONSIDERAÇÕES FINAIS}

T al como nos comentários de José Vasconcelos, mencionados há pouco, o programa verde-amarelo expôs uma disputa pelo direito ao discurso do conhecimento. De forma um pouco esquemática, é possível dizer que, se, por um lado, os ensaístas brasileiros, como Alberto Torres, motivaram os verde-amarelos para o elogio da objetividade e a busca do Brasil Real e presente, por outro lado, José de Vasconcelos os fizera mirar o futuro e continuar valorizando a intuição. Ao fim, como se pode notar pelo Manifesto Nhengaçu de 1929, a concepção de Plínio Salgado de que o brasileiro teria herdado do indígena a predisposição para o contato harmonioso com todos os povos se impôs (Picchia et. al. 17 mai. 1929).

0 futuro projetado por José Vasconcelos, em 1925, assume contornos mais restritos, na acepção de uma "uma grande nação", a brasileira, que integraria "todas as nossas experiências históricas, étnicas, sociais, religiosas e políticas. Pela força centrípeta do elemento tupi" (Ibidem). Ao mesmo tempo, segundo o manifesto, o nacionalismo brasileiro era essencialmente sentimental e uma não filosofia, que seria a continuação do seu destino histórico, sem imposições temáticas e imperativos ideológicos, tidos como elementos externos à brasilidade. Por essa razão, segundo os verde-amarelos, "podemos destruir nossas bibliotecas, sem a menor consequência no metabolismo funcional dos órgãos vitais da nação" (Ibidem).

A denúncia da "tirania das sistematizações ideológicas" resulta, paradoxalmente, na imposição da fórmula do "ser brasileiro" e na interpretação do país sob um ângulo pessoal ou da "própria determinação instintiva" (Ibidem). Numa espécie de balanço do modernismo desde 1922, os autores do manifesto propõem o encerramento das discussões literárias, em favor da produção e da ampliação do movimento modernista, e lamentam que os escritores tenham sido até então seu próprio público. Assim, faziam o convite à sua geração de "produzir sem discutir. Bem ou mal, mas produzir. [...] escrever sem espírito pré-concebido, não por mera experiência de estilos, ou para veicular teorias" (Ibidem).

Nos fins da década de 1920, o verde-amarelismo se constituiu em debate com outras correntes do modernismo e na discussão sobre aos erros da República, considerando diagnóstico euclidiano dos dois Brasis, e do sertão marcado pelo abandono, mas também pela autenticidade, e o do litoral, portador da civilização e dos riscos da imitação. Os verde-amarelos resolveriam esse tema, propondo uma síntese entre o litoral e o sertão, bem como, com base nas leituras da obra de José Vasconcelos, uma nova raça, miscigenada. Com essas reflexões, chamei a atenção para a aproximação do verde-amarelismo com o ensaísmo, esperando sugerir possibilidades de leitura e de reconhecimento de trechos menos transitados pela historiografia do modernismo paulista. Ao mesmo tempo, procurei destacar uma face menos caipira dos verde-amarelos, tomando-os como atores do cenário intelectual dos anos 1920, os quais, como outros atores de seu tempo, elegeram seus interlocutores e os mobilizaram na elaboração de um discurso sobre a brasilidade. 
ENSAIO E INTERPRETAÇ̃̃O DO BRASIL NO MODERNISMO VERDE-AMARELO (1926-1929)

\section{NOTAS}

1 A denominada vertente verde-amarela do modernismo paulista se formou em meados de 1925, em contraponto à poesia Pau-Brasil de Oswald de Andrade. 0 Correio Paulistano, ligado ao PRP, partido tradicional das elites cafeicultoras de São Paulo, foi o principal veículo de divulgação da ideologia verde-amarela. Além de Cassiano Ricardo, Menotti Del Picchia e Plínio Salgado, reuniu ainda Candido Motta Filho e Alfredo Ellis Junior, cujas obras integraram a "coleção brasiliana" da editorial Hélios, de Cassiano Ricardo e Menotti Del Picchia, coleção que reuniu poesias, estudos históricos e ensaios sobre o Brasil, e assinaram o chamado Manifesto Nhengaçu Verde-Amarelo (1929). Agenor Barbosa, Oliveira Vianna, Alarico da Silveira e Raul Bopp, que posteriormente se reuniu com Oswald de Andrade na Revista de Antropofagia, também foram próximos do grupo.

2 Faço referência a Casa-grande \& senzala (1933), de Gilberto Freyre; a Raízes do Brasil (1936), de Sérgio Buarque de Holanda; e a Marcha para Oeste (1940), de Cassiano Ricardo, entre outros. Por outro lado, considero também que, a partir dos anos 1930, foi mais frequente o investimento dos verde-amarelos na escrita ensaística, o que resultou em livros como A crise da democracia: pesquisa de políticas e sociologias contemporâneas (1931), de Menotti Del Picchia, Alberto Torres e o problema da nossa geração (1931), de Candido Motta Filho, Pequeno ensaio de bandeirologia (1959), de Cassiano Ricardo, entre outros.

3 Ainda que a relação com a Novíssima tenha sido equivalente à que estabeleceram com outros periódicos paulistas da época, é interessante que a publicação tenha procurado o estreitamento desses vínculos, inclusive nomeando o tradutor argentino Benjamim de Garay como representante da revista nas repúblicas sul-americanas (Novíssima, mar.-abr.1924: 2). Cabe ressaltar Manuel Gálvez como um escritor mais identificado com a direita argentina e, em contrapartida, Nicolás Olivari como autor ligado ao grupo de Boedo, à esquerda.

40 nacionalismo, a produção de diagnósticos e receituários para a nação e suas intercessões com os sentidos de moderno, modernidade e modernismo, nos começos do século XX e especialmente nos anos 1920, foram estudados por Luca (1999), Motta (1992), Oliveira (1990), Velloso (2003), entre outros.

5 A discussão sobre sinceridade é ampla e pode ter matrizes diversas. A esse respeito, ver Trilling (1971) e Milnes e Timothy (2010).

6 Ao que parece, a editorial Hélios funcionou entre 1926 e 1928 e seu catálogo foi além de títulos dos participantes do verde-amarelismo, incluindo Os romances do exílio (1927), de Oswald de Andrade, Pathé-Baby (1926), Brás, Bexiga e Barra Funda (1927) e Laranja da China (1928), de Antônio de Alcântara Machado.

7 Exemplar disponível na Série Antropologia, Subsérie Raça, Dossiê Estudos de Populações do Arquivo de Edgard Roquette-Pinto da Academia Brasileira de Letras, no Rio de Janeiro.

8 Cabe investigar se, no Brasil, essa desestabilização do Ocidente como referencial cultural hegemônico coincidiu com a expressão de um orientalismo invertido, como ocorreu no contexto intelectual argentino do mesmo período, segundo Bergel (2015), e se teria implicado também aqui uma sensibilidade prototerceiro-mundista.

9 Em Marcha para Oeste (1940), Cassiano Ricardo usa uma metáfora semelhante ao escrever sobre o caminho paulista da Serra do Mar, cuja travessia faria os portugueses esquecerem os preconceitos trazidos da Europa.

10 No que recorda o ponto de vista do antropólogo Edgard Roquette-Pinto, quando consultado por 0 Jornal sobre a imigração japonesa: "Por princípio julgo muito vantajosa toda imigração espontânea que nos traga gente sadia, trabalhadora, ordeira, de apreciável nível cultural, seja qual for a sua origem. [...]. Que nos im- 
porta que conservem aqui a sua religião, o seu idioma, [...] se é gente disposta a obedecer às nossas leis e às nossas autoridades, se é gente que vai trabalhar na lavoura, levando para os nossos campos uma educação social e higiênica" (2 maio 1924).

11 Essa perspectiva de um sentido histórico como sucessão de civilizações, que repetem períodos de ascensão, apogeu e declínio, cabe ressaltar, se tornou bastante conhecida nos países latino-americanos com a circulação de A decadência do Ocidente (1918), de Oswald Spengler, que, como visto, não passou despercebido aos modernistas verde-amarelos.

\section{REFERÊNCIAS BIBLIOGRÁFICAS}

ASCENSO, João Gabriel da Silva. A redenção cósmica do mestiço: inversão semântica do conceito de raça na Raza cósmica de José Vasconcelos. Estudos Históricos, v. 26, n. 52, p. 294-315, dez. 2013.

BERGEL, Martín. El Oriente desplazado: los intelectuales y los orígenes del tercermundismo en la Argentina. Bernal: Universidad Nacional de Quilmes Editorial, 2015.

BERRIEL, Carlos Eduardo Ornelas. O trânsito filosófico de Macunaíma. In: . Dimensões de Macunaíma: filosofia, gênero e época. Dissertação (mestrado em teoria literária) - Instituto de Estudos da Linguagem, Universidade Estadual de Campinas, Campinas, São Paulo, 1987.

COELHO, George Leonardo Seabra. Consumo cultural do pensamento vasconceliano na literatura modernista brasileira: intercâmbios intelectuais na constituiç̧ão do discurso da raça latino-americana na década de 1920. Revista Eletrônica da Anphlac, n. 25, jul.-p. 183-221, dez. 2018.

CUCCAGNA, Claudio. Utopismo modernista. São Paulo: Hucitec, 2014.

EL-DINE, Lorenna Ribeiro Zem. A alma e a forma do Brasil: o modernismo paulista em verde-amarelo (anos 1920). Tese (doutorado em história) - Programa de Pós-Graduação em História das Ciências e da Saúde, Casa de Oswaldo Cruz, Fundação Oswaldo Cruz, Rio de Janeiro, 2017.

Eugenia e seleção imigratória: notas sobre o debate entre Alfredo Ellis Junior, Oliveira Vianna e Menotti Del Picchia, 1926. História, Ciências, Saúde - Manguinhos, Rio de Janeiro, v. 23, supl., dez. 2016.

ELLIS, Myriam. Alfredo Ellis Junior (1896-1974). São Paulo: Bentivegna Editora, 1997.

ELLIS JUNIOR, Alfredo . Pedras lascadas. São Paulo: Tipografia Hennes Irmãos \& Cia, 1928.

FARIA, Daniel. As meditações americanas de Keyserling: um cosmopolitismo nas incertezas do tempo. Varia História, Belo Horizonte, v. 29, n. 51, p. 906-907, set.-dez. 2013,.

FILHO, Candido Motta. Alberto Torres e o tema de nossa geração. Rio de Janeiro: Schmidt-Editor-Rio, 1931. . Brasileiros na América. Correio Paulistano, p. 4, 20 jan. 1927.

. Retratos do Brasil. Correio Paulistano, p. 2, 30 nov. 1928.

GUELFI, Maria Lúcia Fernandes. Novíssima: estética e ideologia na década de 1920. São Paulo: USP/Instituto de Estudos Brasileiros, 1987.

HÉLIOS, Aristophanes; PICCHIA, Menotti del. Crônica social: verde e amarelo. Correio Paulistano, p. 3, 23 set. 1925. 
ENSAIO E INTERPRETAÇÃO DO BRASIL NO MODERNISMO VERDE-AMARELO (1926-1929)

JARDIM, Eduardo. A brasilidade modernista: sua dimensão filosófica. Ed. rev. e atual. Rio de Janeiro: Editora PUC-Rio/Ponteio, 2016.

JOHNSON, Randal. Notes On A Conservative Vanguard: The Case of Verde-Amarelo/Anta. Hispanic Studies Series, v. 4, p. 31-42, 1988.

LEPENIES, Wolf. As três culturas. São Paulo: Edusp, 1996.

LIMA, Nísia Trindade. Um sertão chamado Brasil: intelectuais e representação geográfica da identidade nacional. Rio de Janeiro: Revan/luperj/Ucam, 1999.

; HOCHMAN, Gilberto. Condenado pela raça, absolvido pela medicina: o Brasil descoberto pelo movimento sanitarista da Primeira República. In: MAIO, Marcos Chor; SANTOS, Ricardo Ventura dos. (Orgs.). Raça, ciência e sociedade. Rio de Janeiro: Fiocruz/CCBB, 1996, p. 23-40.

LINO, Sonia Cristina. Onde está Waldo Frank? God bles a América Hispânica. Estudos Históricos, Rio de Janeiro, v. 22, n. 44, p. 522-538, jul.-dez. 2009.

LUCA, Tânia Regina de. A revista do Brasil: um diagnóstico para a (n)ação. São Paulo: Fundação Editora Unesp, 1999.

MARTINS, Maro Lara. Interesse e virtude: a sociologia modernista dos anos 1930. Tese (doutorado em sociologia) - Instituto de Estudos Sociais e Políticos, Universidade do Estado do Rio de Janeiro, Rio de Janeiro, 2013.

MILNES, Timothy; SINANAN, Kerry (Eds.). Romanticism, Sincerity and Authenticity. Basingstoke: Palgrave Macmillan, 2010.

MOREIRA, Luiza Franco. Meninos, poetas e heróis: aspectos de Cassiano Ricardo do modernismo ao Estado Novo. São Paulo: Edusp, 2001.

MOTTA, Marly Silva da. A nação faz 100 anos: a questão nacional no centenário da Independência brasileira. Rio de Janeiro: Editora FGV/CPDOC, 1992.

NETTO, Adriano Bittarães. Antropofagia oswaldiana: um receituário estético e científico. São Paulo: Annablume, 2004.

OLIVEIRA, Lúcia Lippi. A questão nacional na Primeira República. São Paulo: Brasiliense/ Brasília: CNPq, 1990.

PICCHIA, Menotti del et al. Anta, Loba ou Manitôs. Correio Paulistano, p. 3, 12 jan. 1927.

Energia destrutiva. Correio Paulistano, p. 3, 6 jul. 1927.

. Mirassol, a cidade de nome lindo. Correio Paulistano, p. 3, 21 abr. 1928.

. 0 atual momento literário. Correio Paulistano, p. 2, 17 maio 1929.

. 0 fenômeno Couto-Porchat. Correio Paulistano, p. 3, 7 abr. 1927.

. 0 problema racial. Correio Paulistano, p. 3, 26 ago. 1926.

. Caapora. Correio Paulistano, p. 2, 27 mai. 1928.

. Minha Terra tem palmeiras. Correio Paulistano, p. 4, 11 jan. 1927.

. Ruminantes de Cultura. Correio Paulistano, p. 3, 7 set. 1926. 
RICUPERO, Bernardo. 0 "original" e a "cópia" na antropofagia. Sociologia \& Antropologia, Rio de Janeiro, v. 8, n. 3, p. 875-912, set.-dez. 2018.

ROQUETTE-PINTO, Edgar. Imigração japonesa: opinião do professor Roquette-Pinto. Correio da Manhã, p. 2, 2 maio 1924.

SÁ, Dominichi Miranda de. A ciência como profissão: médicos, bacharéis e cientistas no Brasil (1895-1935). Rio de Janeiro: Editora Fiocruz, 2006.

SALGADO, Plínio. A Anta e o Curupira. In: . Despertemos a nação. São Paulo: Editora das América, 1955.

. A questão da Anta. Correio Paulistano, p. 3, 23 jan. 1927.

. Formação nacional. Correio Paulistano, p. 3, 19 maio 1926.

SKIRIUS, John. Este centauro de los géneros. In: El ensayo hispano-americano del siglo XX. Cidade do México: Fondo de Cultura Económica, 2006, p. 9-32.

SILVEIRA, Alarico. 0 sonho da raça. Novíssima, São Paulo/Rio de Janeiro, ano 1, n. 8, nov.-dez. 1924, p.11.

TRILLING, Lionel. Sinceridade e autenticidade: a vida em sociedade e a afirmação do eu. São Paulo: É Realizações, 2014.

VASCONCELOS, José. La raza cósmica: misión de la raza iberoamericana. Buenos Aires: Espasa-Calpe Argentina, 1948 [1925].

VELLOSO, Monica Pimenta. 0 modernismo e a questão nacional. In: FERREIRA, Jorge; DELGADO, Lucila de A. Neves. O Brasil republicano e o tempo do liberalismo oligárquico: da proclamação da República à Revolução de 1930. Rio de Janeiro: Civilização Brasileira, 2018.

. 0 mito da originalidade brasileira: a trajetória intelectual de Cassiano Ricardo (dos anos 20 ao Estado Novo). Dissertação (mestrado em filosofia) - Departamento de Filosofia, Pontifícia Universidade Católica do Rio de Janeiro, Rio de Janeiro, 1983. 